\title{
3 Research Square \\ Photoinduced Electron Transfer Reactions of Water Soluble Porphyrins in Zeolite Environment
}

\section{Anbazhagan Venkattappan ( $\square$ anbu80@gmail.com )}

Vinayaka Mission's Kirupananda Variyar Arts and Science College https://orcid.org/0000-0002-67287312

\section{Kandavelu Velappan}

Bharathidasan University

\section{Renganathan Rajalingam}

Bharathidasan University

\section{Research Article}

Keywords: Zeolite/Porphyrins, Electron Transfer, Fluorescence, Antioxidants

Posted Date: February 20th, 2021

DOl: https://doi.org/10.21203/rs.3.rs-207972/v1

License: (c) (1) This work is licensed under a Creative Commons Attribution 4.0 International License. Read Full License

Version of Record: A version of this preprint was published at Journal of Fluorescence on August 2nd, 2021. See the published version at https://doi.org/10.1007/s10895-021-02747-8. 


\section{Photoinduced Electron Transfer Reactions of Water Soluble Porphyrins in \\ Zeolite Environment}

\section{Anbazhagan Venkattappan ${ }^{\mathrm{a}}$, Kandavelu Velappan ${ }^{\mathrm{b}}$, Renganathan Rajalingam ${ }^{\mathrm{b}}$}

a Department of Chemistry, Vinayaka Mission's Kirupananda Variyar Arts and Science College, Vinayaka Missions Research Foundation (Deemed to be University), Salem 636 308, Tamil Nadu, India

${ }^{\mathrm{b}}$ School of Chemistry, Bharathidasan University, Tiruchirappalli-620 024, Tamil Nadu, India

*Author for correspondence: Anbazhagan Venkattappan

E-mail: anbu80@gmail.com; Mobile No.: +919566658559 


\section{Abstract}

Excited state interactions of zeolite adsorbed porphyrins have been investigated by steady state luminescence quenching technique with certain antioxidants such as reduced glutathione, ascorbic acid and $L$-cysteine. The zeolite supported porphyrins, meso-tetra $\left(N\right.$-methyl-4-pyridyl) porphyrin $\left(\mathrm{H}_{2} \mathrm{TMPyP}^{4+}\right)$ and zinc tetra $(N$-methyl-4-pyridyl $)$ porphyrin $\left(\mathrm{ZnTMPyP}^{4+}\right)$ was prepared and characterized by various techniques such as Diffuse Reflectance Spectra (DRS), Scanning Electron Microscope (SEM), powder X-Ray Diffraction (XRD) and BET surface area. The interaction of zeolites with porphyrins are shown to increase the lifetime of the singlet excited state of porphyrins and decays are biphasic in nature. The splitting of the emission band of porphyrins occurs in 1:1 glycerol: water solution due to the changes in the dielectric of the solvation sphere associated with porphyrin. The Stern-Volmer plots of Io/I vs quencher total concentration [Q] were linear in the whole range of [Q] used. This study revealed effective quenching for zinc porphyrin compared to free base porphyrin. The effect of quenchers and zeolite acidity has also been studied. Quenching rate constant $\left(k_{\mathrm{q}}\right)$ is on the order of $10^{9} \mathrm{M}^{-1} \mathrm{~s}^{-1}$. The quenching reaction obeys Rehm-Weller Equation and is shown to be due to thermodynamically favoured electron transfer from quenchers to the excited singlet state of porphyrins (reductive quenching).

Keywords: Zeolite/Porphyrins, Electron Transfer, Fluorescence, Antioxidants

\section{Introduction}

Photochemical studies of metalloporphyrins have been of great interest in fields extending from chemistry, biology, medicine to optoelectronics [1-5]. Metalloporphyrins are the active sites of numerous proteins whose functions range from oxygen transport and storage (hemoglobin, myoglobin) to electron transport (cytochrome c, cytochrome oxidase) to energy conversion (chlorophyll) [6,7]. They are also used as photosensitizers for 
photodynamic therapy (PDT) of cancer [8,9]. Water soluble porphyrins are also of much interest because of their ability to bind with DNA [10,11], act as photosensitizers in photocatalytic water reduction, oxidation [12] and their potential use in photogalvanic cells [13]. The mechanistic understanding of the transfer of electrons, protons and hydrogen atoms is of greater importance since many photochemical and photobiological processes are based on these primary events. The investigations of the interactions of photoexcited singlet states of the porphyrins by artificial photosensitized electron-transfer reactions [14-18] are very important to mimic photosynthesis as a means of solar energy conversion and storage.

In homogeneous solution, the excited states of porphyrins are not sufficiently longlived for electron transfer quenching. There are several studies on fluorescence quenching of the porphyrins by quinones and nitroaromatics in organic solvents $[19,20]$. The oppositely charged energetic intermediates of the porphyrin and quinones, due to their electrostatic attraction, were found to result in considerable decrease in the efficiency of the photoprocess. Many different host systems have been successfully applied as a means of controlling the efficiency of energy storage by preventing rapid back electron transfer. The net photoionization efficiency in organic assemblies such as cyclodextrins [21], polyelectrolytes [22], colloids [23,24], charged micelles [25,26], vesicles [27,28] and hydrophilichydrophobic environments such as water-in-oil microemulsions [29] are typically higher than that in homogeneous solution, but the photoinduced radicals are not stable at room temperature. In some cases, the photoyields in organic assemblies are limited by the polarity and solubility of the photoactive molecules. Other investigators have explored the design of microheterogeneous assemblies such as zeolites [30-33] and silica gels [34,35] to achieve charge separation. Their cages and pores provide an appropriate microenvironment to retard back electron transfer and increase the lifetime of the photogenerated radicals ion intermediates. This has been accomplished in several cases where reactions between an 
uncharged substrate and/or quencher result in formation of charged products, one of which is selectively expelled or sequestered by the assembly.

In this paper, influence of the antioxidants on the fluorescence behaviour of excited state of porphyrins adsorbed in zeolites in 1:1 glycerol water medium are reported. The effect of sensitizers, quenchers and zeolite acidity has also been studied. The structures of porphyrins and quenchers used in this study are given in scheme 1. The mechanism of quenching and the pathways have been analyzed in terms of singlet excited state porphyrinquencher interaction. The formation of radical ion pairs will be a reason for fluorescence quenching.

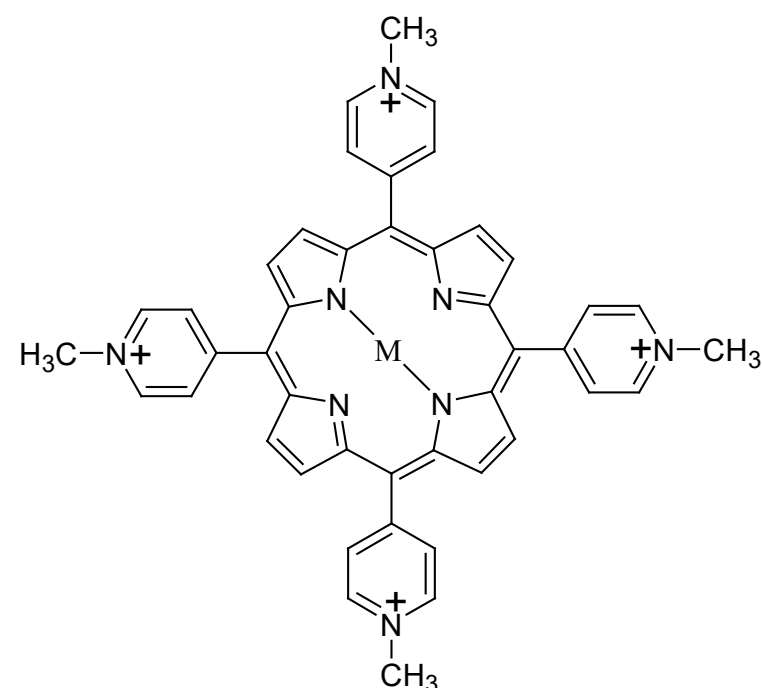

$$
\begin{array}{ll}
\mathrm{M}=2 \mathrm{H} & \mathrm{H}_{2} \mathrm{TMPyP}^{4+} \\
\mathrm{M}=\mathrm{Zn} & \mathrm{ZnTMPyP}^{4+}
\end{array}
$$<smiles>NC(CCC(=O)NC(CS)C(=O)NCC(=O)O)C(=O)O</smiles>

Reduced Glutathione<smiles>O=C1O[C@H](CO)[C@@H](O)[C@H](O)[C@H]1O</smiles>

Ascorbic acid

Scheme 1 Structures of porphyrins and quenchers used in this study

\section{Experimental Section}

The tetra(4-pyridyl) porphyrin (TPyP), methyl-p-toluene sulfonate, dimethyl formamide, reduced glutathione, ascorbic acid, $L$-cysteine and glycerol, zinc acetate, dowex and sephadex were of high purity from Fluka or Aldrich and were used as received. The zeolite-Y (Si/Al: 2.3) was obtained from Mid-Century chemicals and the zeolite Y (Si/Al: 1.6) was prepared by the reported procedure [36]. X-Ray powder diffraction (XRD) pattern 
of the zeolite has excellent agreement with the calculated simulation of the XRD pattern for faujasite zeolite [37].

\section{Preparation of Water Soluble Porphyrins}

$\mathrm{H}_{2} \mathrm{TMPyP}^{4+}$ and $\mathrm{ZnTMPyP}^{4+}$ were synthesized by reported procedure [38]. $\mathrm{H}_{2} \mathrm{TMPyP}^{4+}$ was prepared by methylation of TPyP $(100 \mathrm{mg})$ with methyl-p-toluene sulfonate (500 mg) by refluxing overnight in dimethylformamide. Most of the dimethylformamide was removed by vacuum distillation and the solution was cooled until the precipitation of tosylate salt of $\mathrm{H}_{2} \mathrm{TMPyP}^{4+}$ occurred. The solid was filtered, washed sparingly with cold acetone and air dried. The metal $(\mathrm{Zn})$ insertion was carried out by dissolving $\mathrm{H}_{2} \mathrm{TMPyP}^{4+}$ in water together with 5 fold excess of zinc acetate and stirring the solution overnight. The anion was exchanged by passing the solution through chloride ion enriched resin, subsequently purified with dowex or sephadex columns.

\section{Preparation of Zeolite Adsorbed Porphyrins}

The porphyrin sensitizers $\mathrm{H}_{2} \mathrm{TMPyP}^{4+}$ and $\mathrm{ZnTMPyP}^{4+}$ were adsorbed onto zeolite $\mathrm{Y}$ with varying $\mathrm{Si} / \mathrm{Al}$ ratio (i.e., 2.3 and 1.6) by suspending $1 \mathrm{~g}$ of latter in $25 \mathrm{~mL}$ of water containing $2 \times 10^{-5} \mathrm{M}$ solution of porphyrin. After stirring overnight, the suspension was filtered and washed with water until the washings were colourless. The filtered porphyrin exchanged zeolite powder was washed in a soxhlet extractor with methanol to remove unbound porphyrin, if any and allowed to dry in air. Comparison of the filtered bathing solutions before and after equilibration, by UV-Vis spectroscopy, showed that the loading levels of $\mathrm{H}_{2} \mathrm{TMPyP}^{4+}$ and $\mathrm{ZnTMPyP}^{4+}$ were 0.5 to $1 \times 10^{-5} \mathrm{~mol} / \mathrm{g}$ zeolite. The observed porphyrin loadings correspond to approximately monolayer $\left(10^{-10} \mathrm{~mol} \mathrm{~cm}{ }^{-2}\right)$ coverage $[30,39]$ of the particle external surface. The electrostatic interactions between the anionic aluminosilicate support and the cationic porphyrin molecules contribute to the successful adsorption of the complexes. 


\section{Analyses}

Absorbance spectra were recorded using Hewlett Packard 8452A spectrophotometer and Diffuse Reflectance Spectra (DRS) measurements were performed on CARY 5 UVVisible spectrometer with an integrating sphere reflectance accessory. The X-Ray Diffraction (XRD) patterns of all the catalysts in this study were obtained on a Siemens D5000 X-ray diffractometer using $\mathrm{Ni}$ filtered $\mathrm{Cu} \mathrm{K \alpha}$ radiation $(\lambda=1.5406)$ from $2 \theta=20$ to $60^{\circ}$. A conventional all glass volumetric high vacuum system was employed for the surface area measurements of the catalysts by nitrogen adsorption at liquid nitrogen temperature. Philips XL 30 SFEG instrument was employed for the Scanning Electron Microscope (SEM) measurement.

Fluorescence quenching experiments were carried out using a Perkin Elmer LS 50B spectrofluorimeter. The excitation wavelength was in all cases at or near the maximum of the $\mathrm{Q}(1, \mathrm{O})$ band of the porphyrins. The samples were dispersed by sonication in the desired medium. In the steady-state fluorescence measurements, a known amount of each porphyrin/zeolite sample was dispersed in $3 \mathrm{~mL}$ of the 1:1 glycerol: water solution with various concentrations of quenchers under nitrogen atmosphere and measurements taken at right angles in a $1 \mathrm{~cm}$ cuvette. The concentration of the quencher was normally of the order of $10^{-3} \mathrm{M}$ to $0.1 \mathrm{M}$. Fluorescence lifetimes were measured with a PRA time-correlated singlephoton counting system. Precautions were taken to eliminate spurious single photon counting data arising from scattering of the incident laser flash.

\section{Results and Discussion}

\section{Absorption Studies}

Absorption spectrum of $\mathrm{H}_{2} \mathrm{TMPyP}^{4+}$ and $\mathrm{ZnTMPyP}^{4+}$ in water are identical with those reported in the literature [38] showing the Soret band at $421 \mathrm{~nm}$ and $434 \mathrm{~nm}$ respectively. The shift of the electronic absorption spectra (Soret band) for metal porphyrin was closely 
connected to the electronegativity of the incorporated metal which strongly affects the $\pi$-electron system [40]. In 1:1 glycerol: water solutions, the three major absorption bands are red shifted approximately to $4 \mathrm{~nm}$; adsorption onto the zeolite surface results in a further red shift of $2 \mathrm{~nm}$ in the Soret band and 2-4 $\mathrm{nm}$ in the Q bands. In terms of a band profile or shape, the Soret band is broadened by interaction with the zeolite. The shape of the spectra and band positions indicate the existence of the monomeric dye and non-occurrence of aggregation. The absorption spectra of zeolite adsorbed porphyrins were unaltered in the presence of quenchers. Kano et al [41] reported the ground state complex formation for the $\mathrm{H}_{2} \mathrm{TMPyP}{ }^{4+}$ in the presence of AQDS by observing isosbestic point. The oxidation potential of the quencher used in our case ranges from $-0.45 \mathrm{~V}$ to $0.35 \mathrm{~V}$ and if there is any ground state charge transfer (CT) complex formation, a new absorption peak should appear from the tail end of the $\mathrm{H}_{2} \mathrm{TMPyP}^{4+}$ or $\mathrm{ZnTMPyP}^{4+}$ absorption spectrum. This absorption shall be blue or red shifted depending on the oxidation potential of the quencher. The absence of any such absorption eludes the formation of the ground state complex.

\section{Emission Studies}

Emission spectrum of $\mathrm{H}_{2} \mathrm{TMPyP}^{4+}$ and $\mathrm{ZnTMPyP}^{4+}$ in water were identical with reported literature $[31,38]$. As the porphyrins studied were free-base or closed shell metal porphyrin complexes, the fluorescent emission is attributed to the radiative deactivation of the electronic excited state associated with the porphyrin macrocycle. The emission of freebase porphyrins, like the optical absorption spectra, differ from metallic porphyrin emission due to the differences in their symmetries, the former being significantly red shifted, i.e., the $\lambda_{\max }$ emission is $634 \mathrm{~nm}$ for $\mathrm{ZnTMPyP}^{4+}$ whereas $685 \mathrm{~nm}$ for $\mathrm{H}_{2} \mathrm{TMPyP}^{4+}$. The change in the medium i.e., 1:1 glycerol: water medium, results in marked changes in the fluorescence emission spectrum of $\mathrm{H}_{2} \mathrm{TMPyP}^{4+}$ and $\mathrm{ZnTMPyP}^{4+}$. A blue shift of about 3-5 nm was observed for both porphyrins and the broad fluorescence band of porphyrins gives rise to two 
distinct bands, i.e., $680 \mathrm{~nm}$ and $725 \mathrm{~nm}$ for $\mathrm{H}_{2} \mathrm{TMPyP}^{4+}$ from $685 \mathrm{~nm}, 630 \mathrm{~nm}$ and $672 \mathrm{~nm}$ for $\mathrm{ZnTMPyP}^{4+}$ from $634 \mathrm{~nm}$. The splitting of the emission band of $\mathrm{H}_{2} \mathrm{TMPyP}^{4+}$ has been reported in methanol [42]. This effect is attributed to the changes in the dielectric of the solvation sphere associated with porphyrin. Adsorption onto the zeolite surface results further changes in the fluorescence excitation and emission spectrum of $\mathrm{H}_{2} \mathrm{TMPyP}^{4+}$ and $\mathrm{ZnTMPyP}^{4+}$. A red shift of about $6 \mathrm{~nm}$ in the excitation spectrum was observed for porphyrin-adsorbed zeolites when compared to the excitation spectrum of the free porphyrins. The shift in the emission maxima of $7-25 \mathrm{~nm}$ to lower wavelength (blue shift) was observed for both porphyrins adsorbed in zeolite. The broad fluorescence band of $\mathrm{H}_{2} \mathrm{TMPyP}^{4+}$ shifts 20 $\mathrm{nm}$ and $\mathrm{ZnTMPyP}^{4+}$ shifts $3 \mathrm{~nm}$ to lower wavelength from the fluorescence band observed in 1:1 glycerol: water. The observed broadening in the spectrum is expected due to the interaction with zeolites, which was observed in the case of $\mathrm{ZnTMPyP}^{4+}$ and $\mathrm{ZnTAPP}^{4+}$ on zeolite-L [31]. The photophysical properties of $\mathrm{H}_{2} \mathrm{TMPyP}^{4+}, \mathrm{ZnTMPyP}^{4+}$ in homogeneous solution and on zeolite with varying $\mathrm{Si} / \mathrm{Al}$ ratio are summarized in Table $\mathbf{1}$.

\section{Ground State Reflectance Spectra}

The diffuse reflectance spectra (DRS) were examined to understand the presence and interaction of porphyrin with the zeolite. The UV-Vis DRS of zeolite-Y (Si/Al: 2.3) adsorbed $\mathrm{H}_{2} \mathrm{TMPyP}^{4+}, \mathrm{ZnTMPyP}^{4+}$ are shown in figure 1. The presence of porphyrins was confirmed by the characteristic Soret band of $\mathrm{H}_{2} \mathrm{TMPyP}^{4+}$ and $\mathrm{ZnTMPyP}^{4+}$. Zeolite adsorbed porphyrins showed a red shift of about $6 \mathrm{~nm}\left(427 \mathrm{~nm}\right.$ from $421 \mathrm{~nm}$ for $\mathrm{H}_{2} \mathrm{TMPyP}^{4+}$ and $440 \mathrm{~nm}$ from $434 \mathrm{~nm}$ for ZnTMPyP ${ }^{4+}$ ) in the Soret band when compared to the free porphyrins (not shown in figure). Broadening in the Soret band is expected due to interaction with zeolites. A similar observation was already observed in the case of $\mathrm{ZnTMPyP}^{4+}$ and $\mathrm{ZnTAPP}^{4+}$ adsorbed on zeolite-L [31]. The effects of $\mathrm{Si} / \mathrm{Al}$ ratio and of the nature of the balancing cation seem to 
follow the acid-base properties of zeolites, indicating that the acid and basic sites are responsible for porphyrin adsorption.

\section{BET Surface Area Measurements}

Surface area measurements for the zeolite adsorbed porphyrins and bare zeolites give the information about the presence of porphyrin on the surface. The BET Surface area measurement for the zeolite adsorbed porphyrin catalysts is given in Table 2 . The zeolite adsorbed porphyrins shows reduced surface area compared to bare zeolites. It could be due to the presence of porphyrins on the surface of zeolites.

\section{X-Ray Diffraction Studies}

X-ray powder diffraction permits one to ensure that the zeolite (host) crystallinity remains unaltered after its chemical modification. The X-ray powder diffraction patterns of $\mathrm{H}_{2} \mathrm{TMPyP}^{4+}$ and $\mathrm{ZnTMPyP}^{4+}$ loaded zeolites ( $\mathrm{Si} / \mathrm{Al}: 2.3$ and 1.6) are presented in figure 2. None of the solids showed reduction in the intensity of peaks, suggesting the crystallinity retention of zeolite matrix. The main framework of the zeolite was not damaged. No variation was observed in the zeolite lattice parameters after the adsorption procedures.

\section{SEM Analysis}

The SEM image of porphyrin-zeolite-Y is similar to those observed for zeolite-Y, indicating that they possess the same morphology, i.e., the framework around the guest molecule porphyrin is zeolite-Y. A typical micrographs of zeolite ( $\mathrm{Si} / \mathrm{Al}$ : 1.6) adsorbed $\mathrm{H}_{2} \mathrm{TMPyP}^{4+}$ were shown in figures 3 \& 4. It suggests that the slid support is structurally unchanged and porphyrins should be dispersed molecularly on the external surface.

\section{Lifetime Measurements}

To understand the role of zeolite and the solvent system, the singlet state lifetime $(\tau)$ of porphyrins in water, 1:1 glycerol water and zeolite adsorbed porphyrins system were measured and is shown in Table 1. The singlet state lifetime of $\mathrm{H}_{2} \mathrm{TMPyP}^{4+}$ and $\mathrm{ZnTMPyP}^{4+}$ 
in homogeneous condition is $5.3 \mathrm{~ns}$ and $1.3 \mathrm{~ns}$ respectively [31,38]. For 1:1 glycerol water system, the lifetime of the porphyrins increased by about $\sim 0.2$ ns. Fuorescence decays of porphyrins adsorbed on zeolites were biphasic in nature. The observed difference is due to the presence of zeolite environment and solvent used, which stabilizes the singlet lifetime of porphyrin and it varies with varying $\mathrm{Si} / \mathrm{Al}$ ratio. The acid and basic sites present in zeolites are possibly responsible for the difference observed in lifetime. We can reason that the fast decay comes from a porphyrin ion which interacts strongly with the zeolite surface. This result suggests that singlet-state quenching of porphyrins by the quenchers may occur because of close positioning of the methylpyridinium group of the two molecules.

\section{Fluorescence Quenching}

Fluorescence quenching of zeolite adsorbed porphyrin by various quenchers such as ascorbic acid, reduced glutathione and $L$-cysteine was carried out in 1:1 glycerol: water. The addition of quenchers did not change the porphyrin shape of fluorescence spectra and the absence of any new peak appearance eliminates the possibility of the ground state complex formation. Since there is no complexation between quencher and sensitizer, the water molecules from the solvation shell of the porphyrin remains as such. This, in effect, increases the possibility of collisional quenching of singlet excited state of porphyrins. The absence of CT complex absorption was already reported $[43,44]$ for the quenching of ionic porphyrin by neutral quenchers such as guanine and nitrobenzene. The concentration of quenchers used in this study is enough to quench the fluorescence of porphyrins. The emission intensity declines with the increase in the quencher concentration, which clearly indicates the quenching of porphyrin. Fluorescence quenching spectrum of zeolite-Y (Si/Al: 1.6) adsorbed $\mathrm{H}_{2} \mathrm{TMPyP}^{4+}$ with various concentrations of ascorbic acid in $1: 1$ glycerol: water is shown in figure 5. The Stern-Volmer relationship was used for the analysis of fluorescence quenching [45]. 


$$
\mathrm{I}_{0} / \mathrm{I}=1+\mathrm{K}_{\mathrm{SV}}[\mathrm{Q}]
$$

where $\mathrm{I}_{0}$ and $\mathrm{I}$ are the intensities of the fluorescer in the absence and the presence of quencher, respectively. $\mathrm{K}_{\mathrm{SV}}$ is Stern-Volmer constant and [Q] is the concentration of the quencher.

The bimolecular quenching rate constant, $k_{\mathrm{q}}$ was calculated using equation 2 .

$$
k_{\mathrm{q}}=\mathrm{Ksv} / \tau_{0}
$$

where $\tau_{0}$ is the fluorescence lifetime of the porphyrin in the absence of quencher.

The Stern-Volmer plot of Io/I versus [Q] yields a straight line for the porphyrin fluorescence quenching. In all the cases the correlation coefficient (r) is in the range of $0.99-$ 0.97. A typical plot for the zeolite-Y ( $\mathrm{Si} / \mathrm{Al}: 1.6)$ adsorbed $\mathrm{H}_{2} \mathrm{TMPyP}^{4+}$ with ascorbic acid is shown in figure 6. The process involves purely a dynamic quenching, i.e., quenching solely by collisional deactivation of the singlet excited state. The quenching rate constants for various zeolite adsorbed porphyrins with quenchers such as ascorbic acid, reduced glutathione and $L$-cysteine are shown in Table 3.

The $k_{\mathrm{q}}$ values observed for zeolite adsorbed $\mathrm{H}_{2} \mathrm{TMPyP}^{4+}$ indicates that the quenching efficiency is more for reduced glutathione followed by ascorbic acid and $L$-cysteine. The same trend is observed for zeolite adsorbed $\mathrm{ZnTMPyP}^{4+}$. This effect is due to better electron donating tendency of glutathione than other quenchers such as ascorbic acid and $L$-cysteine. The quenching of $\mathrm{H}_{2} \mathrm{TMPyP}^{4+}$ is slower than its zinc complex, it is due to the fact that zinc complex is better oxidant [38] than its free base porphyrin.

The dependence of $k_{q}$ on zeolites reflects the influence of the difference in the structural features of the two different zeolites ( $\mathrm{Si} / \mathrm{Al}: 2.3$ and 1.6) employed. The effects of $\mathrm{Si} / \mathrm{Al}$ ratio and of the nature of the balancing cation, seem to follow the acid-base properties of zeolites, indicating that the acid and basic sites are possibly responsible for porphyrin adsorption and quenching. The strength of acid and basic sites is mainly determined by its 
cation nature, framework composition and the crystalline nature [46-49]. For zeolite having $\mathrm{Si} / \mathrm{Al}: 2.3$ and 1.6, the difference is the framework composition. A richer aluminium zeolite (Si/Al: 1.6) will present a higher negative framework charge and a stronger basicity when the framework composition is concerned. So the strength of base sites is decreased in the order $\mathrm{Si} / \mathrm{Al}: 1.6>\mathrm{Si} / \mathrm{Al}: 2.3$, while the Lewis acid strength is increased. Higher the acid strength, higher will be the quenching efficiency [50]. Due to the difference in the above properties, the quenching efficiency differs in the following order:

Porphyrin/zeolite-Y (Si/Al: 2.3) > Porphyrin/zeolite-Y (Si/Al: 1.6)

\section{Quenching Mechanism}

The quenching of porphyrins through electron transfer processes has been extensively studied. In number of systems net formation of products is observed when they possess the same charge. On the other hand, when an electron transfer process produces products with opposite charges, quenching of the excited state of the porphyrins leads to no net product formation.

In the present system, only the porphyrin is being excited and the emission spectrum of porphyrin does not overlap with the absorption spectrum of the used quenchers. Therefore, energy transfer from $\mathrm{H}_{2} \mathrm{TMPyP}^{4+}$ and $\mathrm{ZnTMPyP}^{4+}$ to the quenchers cannot be acceptable mechanism for the quenching. Examination of redox potentials of the quenchers and the porphyrins demonstrate that the mechanism of singlet quenching most likely involves electron transfer between excited singlet of porphyrin and the quencher.

The nature of the electron transfer pathway (i.e., oxidative or reductive quenching of the porphyrin singlet state) can be understood by examining the free energy of the corresponding electron transfer reactions. The thermodynamics of electron transfer from the quencher to the porphyrin can be calculated by the well known Rehm-Weller equation [51].

$$
\Delta G_{\text {et }}=E_{1 / 2 \text { (oxid.) }}-E_{1 / 2(\text { red. })}-E_{(0,0)}+C
$$


where $E_{1 / 2 \text { (oxid.) }}$ is the oxidation potential of the donor, $E_{1 / 2 \text { (red.) }}$ is the reduction potential of the acceptor, $E_{(0,0)}$ is the singlet state energy of the sensitizer and $\mathrm{C}$ is the coulombic term. Since one of the species is neutral and the solvent used is polar in nature the coulombic term in the above expression is neglected [52].

The oxidation potential of reduced glutathione, $L$-cysteine and ascorbic acid are -0.35 , -0.45 (vs HMDE) and $0.35 \mathrm{~V}$ (vs SCE) respectively [53-55]. The reduction potential of $\mathrm{H}_{2} \mathrm{TMPyP}^{4+}$ and $\mathrm{ZnTMPyP}^{4+}$ are $-0.23 \mathrm{~V}$ [56] and -1.04 V [30] respectively, whereas the reduction potential changed significantly when they are exchanged into zeolite-Y showing a shift of both the metal and ring waves to more positive values by ca. $200 \mathrm{mV}$, i.e., $-0.06 \mathrm{~V}$ for $\mathrm{H}_{2} \mathrm{TMPyP}^{4+}$ and $-0.85 \mathrm{~V}$ for $\mathrm{ZnTMPyP}^{4+}[30]$. The excited singlet state energy $\left(E_{(0,0)}\right)$ for $\mathrm{H}_{2} \mathrm{TMPyP}^{4+}$ is $1.83 \mathrm{eV}$ and for $\mathrm{ZnTMPyP}^{4+}$ is $1.98 \mathrm{eV}$. Thus, a thermodynamically favorable electron transfer from the quencher to the excited porphyrin will be anticipated only when $E_{1 / 2}\left(\mathrm{DH} / \mathrm{DH}^{\bullet+}\right)$ is less than 1.77 and $1.13 \mathrm{~V}$ for $\mathrm{H}_{2} \mathrm{TMPyP}^{4+}$ and $\mathrm{ZnTMPyP}^{4+}$ respectively. All the quenchers used have less than that oxidation potential value, are expected to reduce the singlet excited state of porphyrins. The possibility of oxidative quenching (i.e., electron transfer from porphyrins to quenchers) can be eliminated due to the high electron donating ability and absence of electron accepting ability of quenchers. Thus it is suggested that observed quenching reaction involves electron transfer from quencher to porphyrin. The reduction of $\mathrm{ZnTMPyP}^{4+}$ like that for $\mathrm{H}_{2} \mathrm{TMPyP}^{4+}$ involve the formation of $\pi$ radical species, i.e., the metal ions are not readily reduced from the +2 state. Scheme 2 is proposed for electron transfer reaction in the present system.

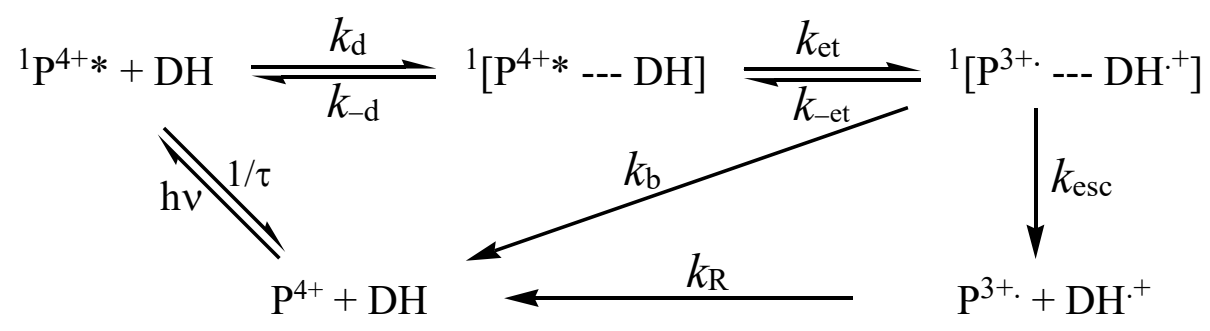


Scheme 2 Mechanism for the luminescence quenching of $\mathrm{P}^{4+*}$ with $\mathrm{DH}$

In scheme $2, \mathrm{P}^{4+}$ and $\mathrm{DH}$ are porphyrins and quenchers respectively. $k_{\mathrm{d}}$ and $k_{-\mathrm{d}}$ are the rate constants of diffusion and dissociation coefficients of the encounter complex, respectively. $k_{\text {et }}$ is the rate constant for the formation of radical ion pair and $k_{\text {-et }}$ is the rate constant for the recombination. $k_{\text {esc }}$ is the rate constant for the separation of the separated radical ion pair and $k_{\mathrm{R}}$ is the rate constant for the recombination of the separated radical ion pair. $k_{\mathrm{b}}$ is the rate constant for the charge recombination reaction producing the acceptor molecule in the ground state.

The radical ion pair either undergoes back electron transfer leading to regeneration of reactants or escape from the solvent cage to give the redox products (eqn. $4 \& 5$ ).

$$
\mathrm{DH}^{\bullet+} \longrightarrow \mathrm{D}^{\bullet}+\mathrm{H}^{+}, 2 \mathrm{D}^{\bullet} \longrightarrow \mathrm{D}-\mathrm{D}
$$

where $\mathrm{DH}=L$-cysteine, reduced glutathione and ascorbic acid.

$$
\mathrm{P}^{3+\bullet} \longrightarrow \text { disproportionation or protonation }
$$

where $\mathrm{P}^{4+}=\mathrm{H}_{2} \mathrm{TMPyP}^{4+}$ and $\mathrm{ZnTMPyP} \mathrm{P}^{4+}$.

The quencher $(\mathrm{DH})$ donates proton after the electron loss and it may be taken by the zeolite since it has the great affinity to take up the proton produced, by preventing the back electron transfer in heterogeneous system.

\section{Conclusions}

The presence of porphyrins on the surface and the crystallinity of zeolite were confirmed by DRS, BET surface area, XRD and SEM analysis. The interaction of zeolites with porphyrins increases the lifetime of the singlet excited state of porphyrins and decays are found to be biphasic. The splitting of the emission band of porphyrins occurs in 1:1 glycerol: water solution, similar to that observed for porphyrins in methanol which is attributed to the changes in the dielectric of the solvation sphere associated with porphyrin. In addition, the interactions cause the broadening of the spectrum. The data presented here demonstrate that 
the quenching of the singlet excited state of porphyrins, $\mathrm{H}_{2} \mathrm{TMPyP}^{4+}$ and $\mathrm{ZnTMPyP}{ }^{4+}$ occurs in the presence of quenchers such as reduced glutathione, ascorbic acid and $L$-cysteine. Quenching studies revealed effective quenching for zinc porphyrin compared to free base porphyrin. Also quenching efficiency is more for glutathione than ascorbic acid and $L$-cysteine and zeolite-Y (Si/Al: 2.3$)$ have high efficiency than zeolite-Y (Si/Al: 1.6). The decrease in fluorescence intensity of porphyrins with quenchers is now shown to be due to thermodynamically favoured electron transfer from quenchers to the excited singlet state of porphyrins (reductive quenching). The quenching reaction is shown to be with electron transfer rate on the order of $10^{9} \mathrm{M}^{-1} \mathrm{~s}^{-1}$. Thus, zeolite-Y are found to be promising heterogeneous hosts for long lived photoinduced charge separation of adsorbed porphyrins.

\section{Author Declarations}

Funding: No funding was received for conducting this study.

Conflicts of interest/Competing interests: Authors have no conflict of interest.

Ethics approval: Not applicable

Consent to Participate: Not applicable

Consent for Publications: Not applicable

Data availability: All data generated or analysed during this study are included in this published article.

Code Availability: Not applicable

Authors' contributions: AV and KV has carried out the experimental parts and prepared the draft of the manuscript. RR has contributed in the revision of the manuscript. 


\section{References}

[1] M. Grätzel, Heterogeneous Photochemcial Electron Transfer, CRC Press, Boca Raton, FL, 1989.

[2] K. Kalyanasundaram, Photochemistry in Microheterogeneous Systems, Academic Press, Orlando, 1987.

[3] B. K. K. Fung, L. Stryer, Biochemistry 17 (1978) 5241.

[4] P. L. Luisi, M. Giomini, M. P. Pileni, B. H. Robinson, Biochim. Biophys. Acta 947 (1999) 209.

[5] K. Müller-Dethlefs, P. Hobza, Chem. Rev. 100 (2000) 143.

[6] L. R. Milgrom, The colors of life: An Introduction to the Chemistry of Porphyrins and Related compounds, Oxford University Press, UK, 1997.

[7] K. M. Kadish, K. M. Smith, R. Guilard, Eds, The Porphyrin Handbook, Academic Press, New York, Vols. 1-10, 2000.

[8] T. J. Dougherty, C. J. Gorner, B. W. Henderson, G. Jori, D. Kessel, M. Korbelik, J. Moan, Q. Peng, Photodynamic Therapy, J. Natl. Cancer Inst. 90 (1998) 889.

[9] R. Bonnett, P. Charlesworth, B. D. Djelal, S. Foley, D. J. McGarvey, T. G. Truscott, J. Chem. Soc. Perkin Trans. 2 (1999) 325.

[10] F. X. Han, R. T. Wheelhouse, L. H. Hurly, J. Am. Chem. Soc. 121 (1999) 3561.

[11] E. Shimada, Y. Mori, RIKEN Review 46 (2002) 22.

[12] E. Borgarello, K. Kalyanasundaram, Y. Okuno, M. Gratzel, Helv. Chim. Acta 64 (1981) 1937.

[13] J. Albery, Acc. Chem. Res. 15 (1982) 142.

[14] D. G. Whitten, J. C. Russel, R. H. Schmell, Acc. Chem. Res. 13 (1980) 83.

[15] M. Greatzel, Acc. Chem. Res. 14 (1981) 376.

[16] K. Kalyanasundaram, Coor. Chem. Rev. 46 (1982) 159.

[17] A. J. Bard, Science 207 (1980) 139.

[18] D. Wróbel, J. Lukasiewicz, H. Manikowski, Dyes and Pigments, 58 (2003) 7.

[19] G. S. Beddard, S. Carlin, L. Harris, G. Porter, C. J. Tredwell, Photochem. Photobiol. 27 (1978) 433.

[20] J. K. Baird, S. P. Escott, J. Chem. Phys. 74 (1981) 6993.

[21] S. Hamai, T. Koshiyama, J. Photochem. Photobiol. A:Chem 127 (1999) 135.

[22] Y. Morishima, S. Nomura, T. Ikeda, M. Seki, M. Kamachi, Macromolecules 28 (1995) 2874. 
[23] I. Willner, J. W. Otvos, M. Calvin, J. Am. Chem. Soc. 103 (1981) 3203 .

[24] I. Willner, J. M. Yang, J. W. Otvos, M. Calvin, J. Phys. Chem. 85 (1981) 3277.

[25] Y. Morishma, H. Aota, K. Saegusa, M. Kamachi, Macromolecules 29 (1996) 6505.

[26] S. M. B. Costa, P. L. Cornejo, D. M. Togashi, C. A. T. Laia, J. Photochem. Photobiol. A $142(2001) 151$.

[27] F. M. Menger, M. I. Angelova, Acc. Chem. Res. 31 (1998) 300.

[28] P. I. G. Coutinho, S. M. B. Costa, J. Photochem. Photobiol. A, 82 (1994) 149.

[29] D. M. Togashi, S. M. B. Costa, Phys. Chem. Chem. Phys. 4 (2002) 1141.

[30] Z. Li, C. M. Wang, L. Persuad, T. E. Mallouk, J. Phys. Chem. 92 (1988) 2592.

[31] L. Persuad, A. J. Bard, A. Campion, M. A. Fox, T. E. Mallouk, S. E. Webber, J. M. White, J. Am. Chem. Soc. 109 (1987) 7309.

[32] J. K. Thomas, Chem. Rev. 93 (1993) 301.

[33] M. Borja, P. K. Dutta, Nature 362 (1993) 43.

[34] K. Matsuura, L. Kevan, J. Phys. Chem. 100 (1996) 10652.

[35] F. Wilkinson, D. R. Worrall, S. L. Williams, J. Phys. Chem. 99 (1995) 6689.

[36] B. Zhan, X. Li, Chem. Commun. (1998) 349.

[37] M. M. J. Treacy, J. B. Higgins, R. Von Ballmos, Collection of Simulated XRD Powder Pattterns for Zeolites, Elsevier, 3rd Edn., 1996.

[38] K. Kalyanasundaram, M. Neumann-Spallart, J. Phys. Chem. 86 (1982) 5163.

[39] R. W. Murray, Electroanalytical Chemistry; A. J. Bard, Ed., Dekker, New York, Vol. 13, 1984, p 19.

[40] L. P. Vernon, G. R. Seely, The Chlorophylls, New York, London: Academic Press; 1996.

[41] K. Kano, T. Sato, S. Yamada, T. Ogawa, J. Phys. Chem. 87 (1983) 566.

[42] A. M. Brun, A. Harrimann, J. Am. Chem. Soc., 116 (1994) 10383.

[43] G. S. Nahor, J. Rabani, J. Phys. Chem. 89 (1985) 2468.

[44] R. Jasuja, D.M. Jameson, C.K. Nishijo, R.W. Larsen, J. Phys. Chem. B 101 (1997) 1444.

[45] O. Stern, M. Volmer, Z. Phys. 20 (1919) 183.

[46] D. Barthomeuf, J. Phys. Chem. 88 (1984) 42.

[47] D. Barthomeuf, Stud. Surf. Sci. Catal. 65 (1991) 157.

[48] M. Huang, S. Kaliaguine, J. Chem. Soc. Faraday Trans. 88 (1992) 751.

[49] M. Huang, A. Adnot, S. Kaliaguine, J. Catal. 137 (1992) 322. 
[50] P. P. Levin, S. M. B. Costa, J. M. Lopes, F. N. Serralha, F. R. Ribeiro, Spectrochim. Acta A 56 (2000) 1745.

[51] D. Rehm, A. Weller, Isr. J. Chem. 8 (1970) 259.

[52] P. Ramamurthy, S. Parret, F. M. Savary, J. P. Fouassier, J. Photochem. Photobiol. A 83 (1994) 205.

[53] R. Kizek, J. Vacek, L. Trnková, F. Jelen, Bioelectrochem. 63 (2004) 19.

[54] M. Heyrovský, P. Mader, S. Vavřička, V. Veselá, M. Fedurco, J. Electroanal. Chem. 430 (1997) 103.

[55] G. M. Mabbott, J. Chem. Educ. 60 (1983) 697.

[56] G. S. Nahor, J. Rabani, F. Grieser, J. Phys. Chem. 85 (1981) 1981. 


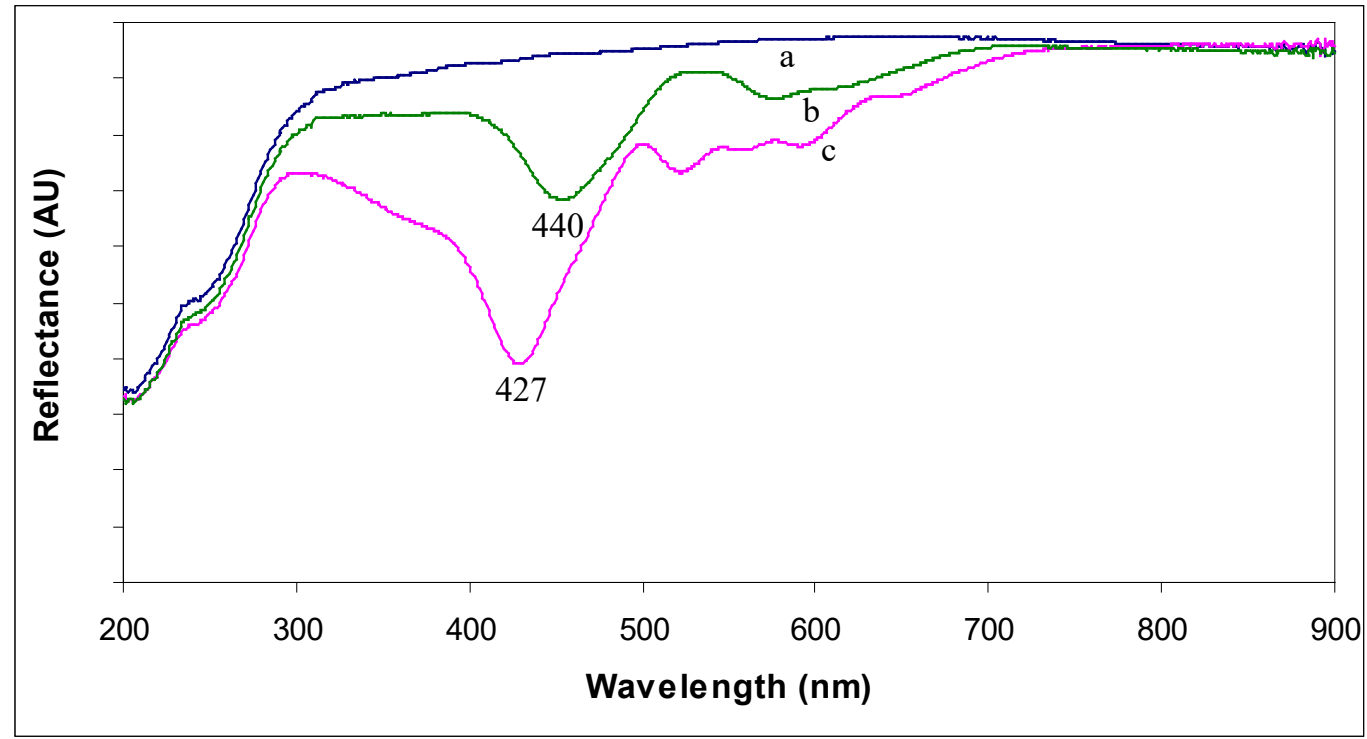

Figure 1. UV-Vis diffuse reflectance spectra of zeolite-Y (Si/Al:2.3) (a) adsorbed $\mathrm{ZnTMPyP}^{4+}$ (b) and $\mathrm{H}_{2} \mathrm{TMPyP}^{4+}$ (c).

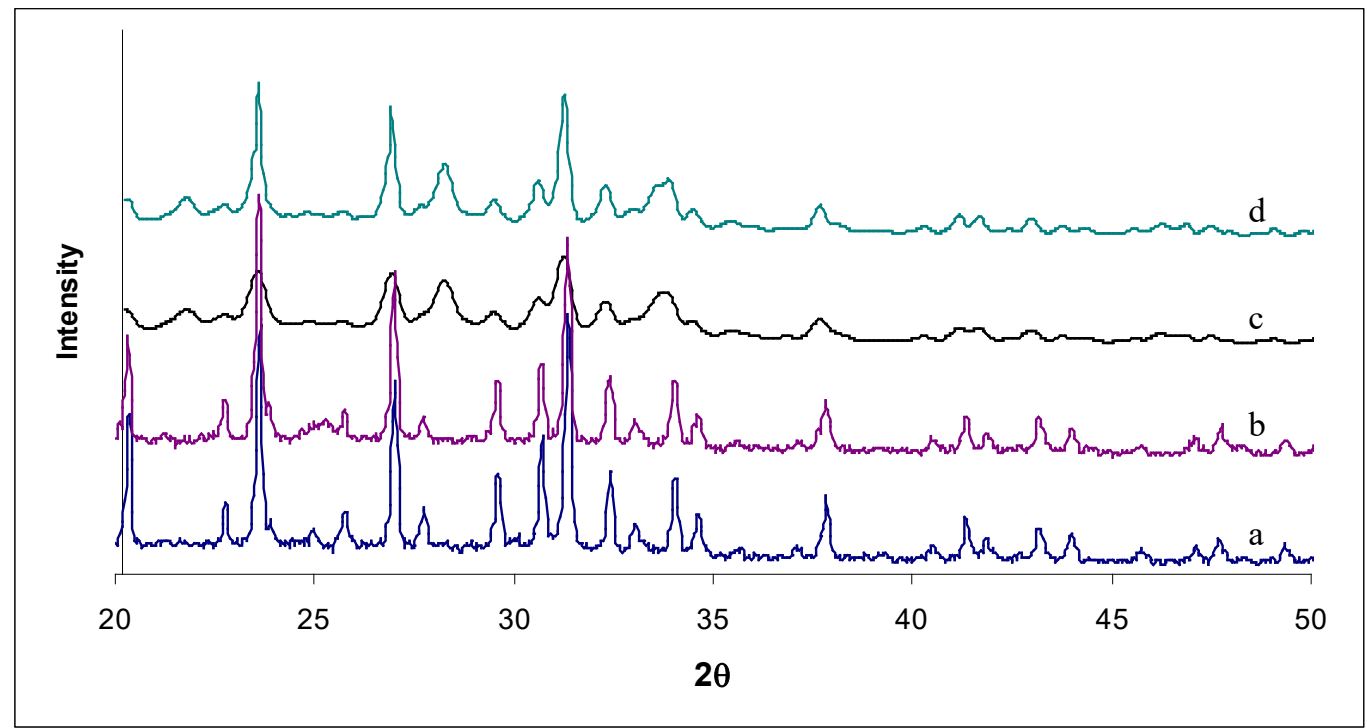

Figure 2. Powder X-ray diffraction pattern of zeolite-Y (Si/Al:2.3) (a), zeolite-Y ( $\mathrm{Si} / \mathrm{Al}: 2.3)$ adsorbed $\mathrm{H}_{2} \mathrm{TMPyP}^{4+}$ (b), zolite-Y (Si/Al: 1.6) (c) and zeolite-Y (Si/Al:2.3) adsorbed $\mathrm{ZnTMPyP}^{4+}(\mathrm{d})$. 


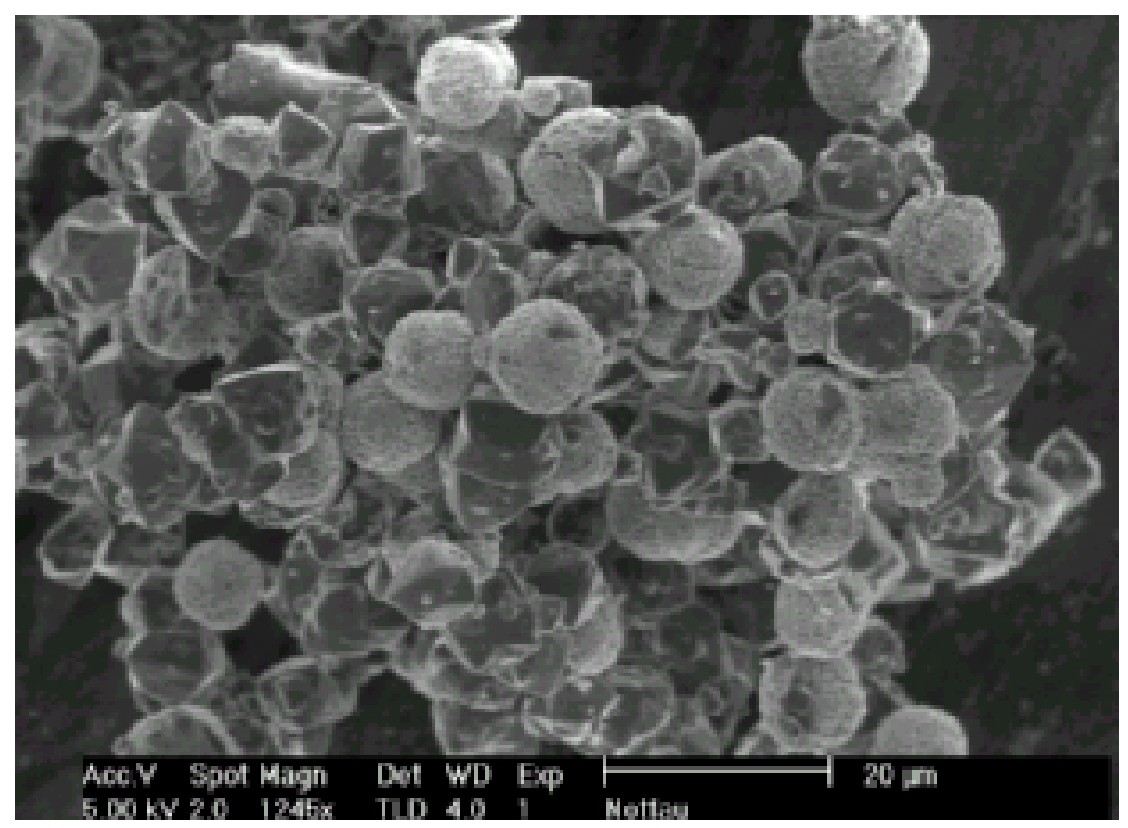

Figure 3. Scanning electron microscope image of zeolite-Y (Si/Al: 1.6) adsorbed $\mathrm{H}_{2} \mathrm{TMPyP}^{4+}$.

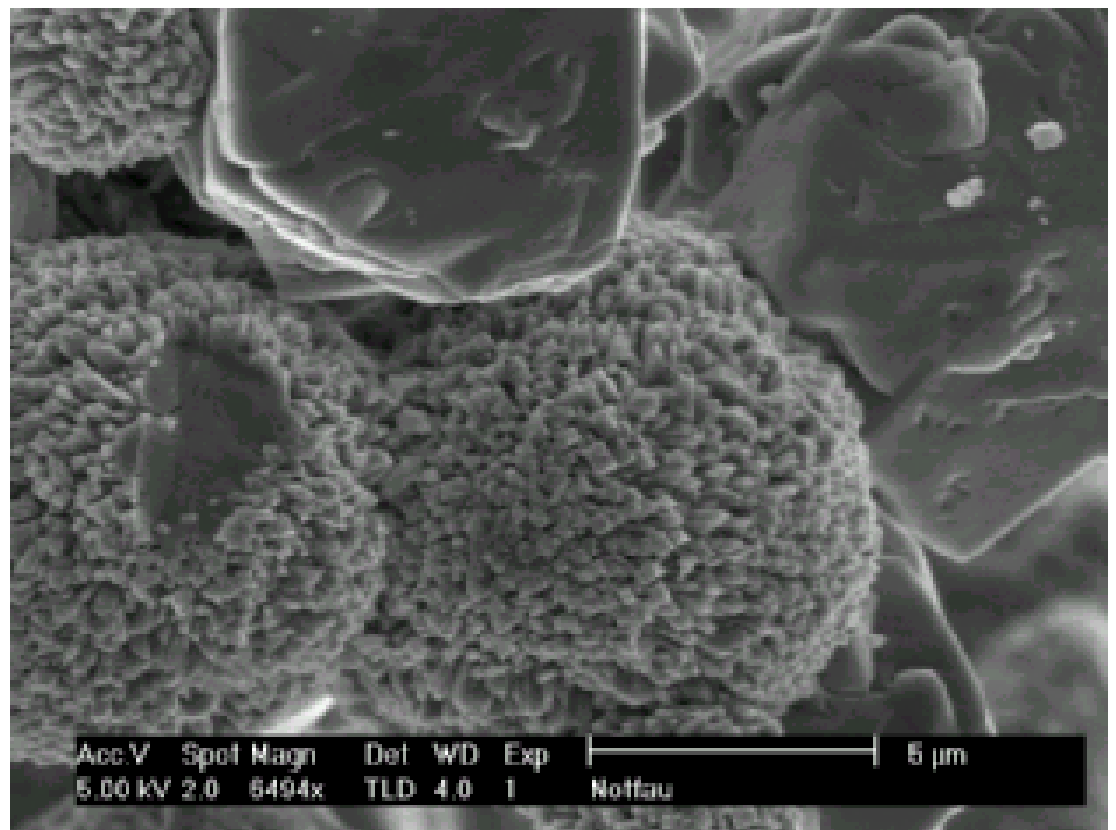

Figure 4. Scanning electron microscope image of zeolite-Y (Si/Al: 1.6) adsorbed $\mathrm{H}_{2} \mathrm{TMPyP}^{4+}$. 


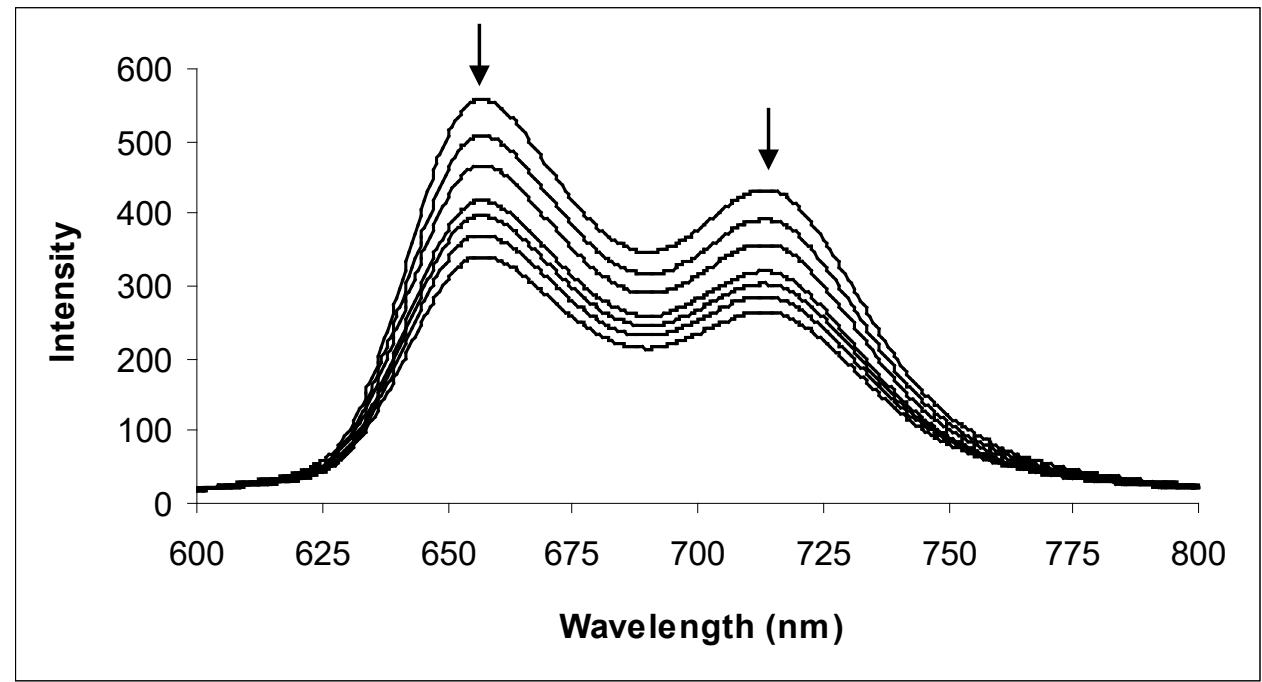

Figure 5. Fluorescence quenching of zeolite- $\mathrm{Y}(\mathrm{Si} / \mathrm{Al}$ : 1.6$)$ adsorbed $\mathrm{H}_{2} \mathrm{TMPyP}^{4+}$ with various concentrations of ascorbic acid $\left(0-9.75 \times 10^{-3} \mathrm{M}\right)$ in 1:1 glycerol: water.

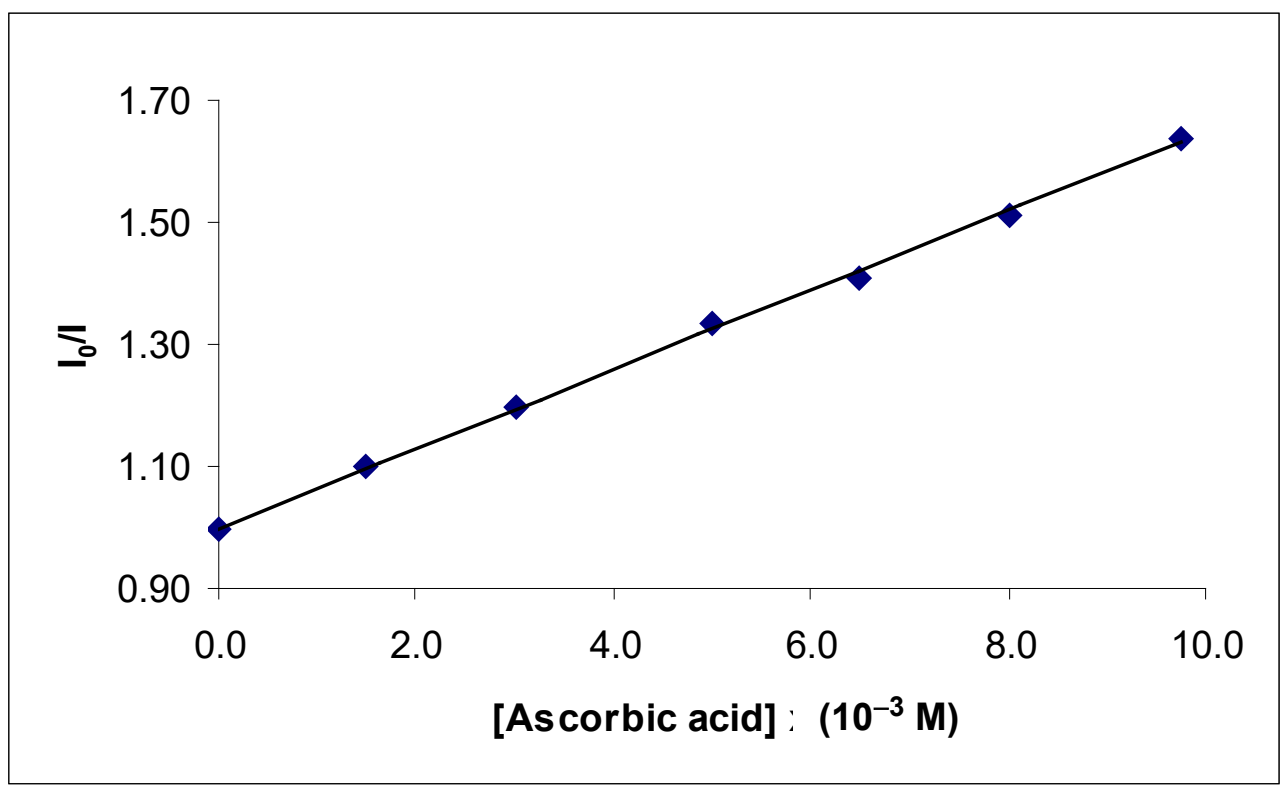

Figure 6. Stern-Volmer plot for the fluorescence quenching of zeolite-Y (Si/Al: 1.6) adsorbed $\mathrm{H}_{2} \mathrm{TMPyP}^{4+}$ with various concentrations of ascorbic acid $\left(0-9.75 \times 10^{-3} \mathrm{M}\right)$ in $1: 1$ glycerol: water. 
Table 1. Physical properties of $\mathrm{H}_{2} \mathrm{TMPyP}^{4+}$ and $\mathrm{ZnTMPyP}^{4+}$ in water, 1:1 glycerol: water and on the zeolite-Y surface ${ }^{d}$

\begin{tabular}{|c|c|c|c|c|}
\hline \multirow{2}{*}{ Property } & \multirow{2}{*}{$\mathrm{H}_{2} \mathrm{O}$} & \multirow{2}{*}{ Glycerol } & \multicolumn{2}{|c|}{ Zeolite-Y } \\
\hline & & & $\mathrm{Si} / \mathrm{Al}: \mathbf{1 . 6}$ & $\mathrm{Si} / \mathrm{Al}: 2.3$ \\
\hline \multicolumn{5}{|l|}{$\mathrm{H}_{2} \mathrm{TMPyP}^{4+}$} \\
\hline \multirow{4}{*}{$\begin{array}{l}\text { Electronic absorption } \\
\text { wavelength maximum, nm }\end{array}$} & 421 & 425 & \multicolumn{2}{|c|}{427} \\
\hline & 520 & 525 & \multicolumn{2}{|c|}{528} \\
\hline & 560 & 565 & \multicolumn{2}{|c|}{567} \\
\hline & 585 & 589 & \multicolumn{2}{|c|}{591} \\
\hline \multirow{2}{*}{$\begin{array}{l}\text { Fluorescence emission } \\
\text { wavelength maximum, } \mathrm{nm}\end{array}$} & \multirow[t]{2}{*}{685} & 680 & \multicolumn{2}{|c|}{660} \\
\hline & & 725 & \multicolumn{2}{|c|}{720} \\
\hline \multirow[t]{2}{*}{$\tau_{\mathrm{F}} / \mathrm{ns}$, fluorescence lifetime } & \multirow[t]{2}{*}{$5.3^{\mathrm{a}}$} & 5.52 & \multirow{2}{*}{$\begin{array}{l}5.49(77.32)^{\mathrm{b}} \\
9.54(32.68)^{\mathrm{c}}\end{array}$} & $5.43(60.90)^{\mathrm{b}}$ \\
\hline & & & & $8.75(39.10)^{\mathrm{c}}$ \\
\hline \multicolumn{5}{|l|}{$\mathrm{ZnTMPyP}^{4+}$} \\
\hline \multirow{3}{*}{$\begin{array}{l}\text { Electronic absorption } \\
\text { wavelength maximum, nm }\end{array}$} & 434 & 438 & \multicolumn{2}{|c|}{440} \\
\hline & 560 & 562 & \multicolumn{2}{|c|}{566} \\
\hline & 600 & 602 & \multicolumn{2}{|c|}{606} \\
\hline \multirow{2}{*}{$\begin{array}{l}\text { Fluorescence emission } \\
\text { wavelength maximum, nm }\end{array}$} & \multirow[t]{2}{*}{634} & 630 & \multicolumn{2}{|c|}{627} \\
\hline & & 672 & \multicolumn{2}{|c|}{670} \\
\hline \multirow[t]{2}{*}{$\tau_{\mathrm{F}} / \mathrm{ns}$, fluorescence lifetime } & \multirow[t]{2}{*}{$1.3^{\mathrm{a}}$} & \multirow[t]{2}{*}{1.53} & $1.45(83.50)^{\mathrm{b}}$ & $1.41(68.47)^{\mathrm{b}}$ \\
\hline & & & $4.78(16.50)^{\mathrm{c}}$ & $6.37(31.53)^{\mathrm{c}}$ \\
\hline
\end{tabular}

${ }^{\mathrm{a}}$ from ref $[3,8],{ }^{\mathrm{b}}$ fast component, ${ }^{\mathrm{c}}$ slow component, in 1:1 glycerol: water, biphasic decay,

${ }^{\mathrm{d}}$ Error limits: $\tau_{\mathrm{F}}, \pm 20 \%$. 
Table 2. Surface area of various zeolite-Y adsorbed porphyrins

\begin{tabular}{|c|c|}
\hline Zeolite adsorbed Porphyrin & Surface Area $\left(\mathrm{m}^{2} \mathrm{~g}^{-1}\right)$ \\
\hline Zeolite-Y (Si/Al: 2.3) & 652 \\
\hline $\mathrm{H}_{2} \mathrm{TMPyP}^{4+} /$ Zeolite -Y (Si/Al: 2.3) & 640 \\
\hline ZnTMPyP4+ / Zeolite -Y (Si/Al: 2.3) & 642 \\
\hline Zeolite -Y (Si/Al: 1.6) & 660 \\
\hline $\mathrm{H}_{2} \mathrm{TMPyP}^{4+} /$ Zeolite -Y (Si/Al: 1.6) & 645 \\
\hline ZnTMPyP ${ }^{4+} /$ Zeolite -Y (Si/Al: 1.6) & 650 \\
\hline
\end{tabular}

Table 3. Free energy change for electron transfer and quenching rate constant for the porphyrins in zeolites with various quenchers

\begin{tabular}{|c|c|c|c|c|c|c|}
\hline \multirow{3}{*}{ Quencher } & \multicolumn{3}{|c|}{$\mathrm{H}_{2} \mathrm{TMPyP}^{4+}$} & \multicolumn{3}{|c|}{ ZnTMPyP ${ }^{4+}$} \\
\hline & \multirow{2}{*}{$\Delta G_{\text {et }}(\mathrm{eV})$} & \multicolumn{2}{|c|}{$k_{\mathrm{q}}\left(10^{9} \mathrm{M}^{-1} \mathrm{~s}^{-1}\right)$} & \multirow{2}{*}{$\Delta G_{\text {et }}(\mathrm{eV})$} & \multicolumn{2}{|c|}{$k_{\mathrm{q}}\left(10^{9} \mathrm{M}^{-1} \mathrm{~s}^{-1}\right)$} \\
\hline & & Z-Y(2.3) & Z-Y(1.6) & & Z-Y(2.3) & Z-Y(1.6) \\
\hline $\begin{array}{l}\text { Reduced } \\
\text { glutathione }\end{array}$ & -2.12 & 16.99 & 14.20 & -1.48 & 52.05 & 48.27 \\
\hline $\begin{array}{l}\text { Ascorbic } \\
\text { acid }\end{array}$ & -1.42 & 15.30 & 11.76 & -0.78 & 32.12 & 29.03 \\
\hline$L$-Cysteine & -2.22 & 2.96 & 2.55 & -1.58 & 9.14 & 5.17 \\
\hline
\end{tabular}


Figures

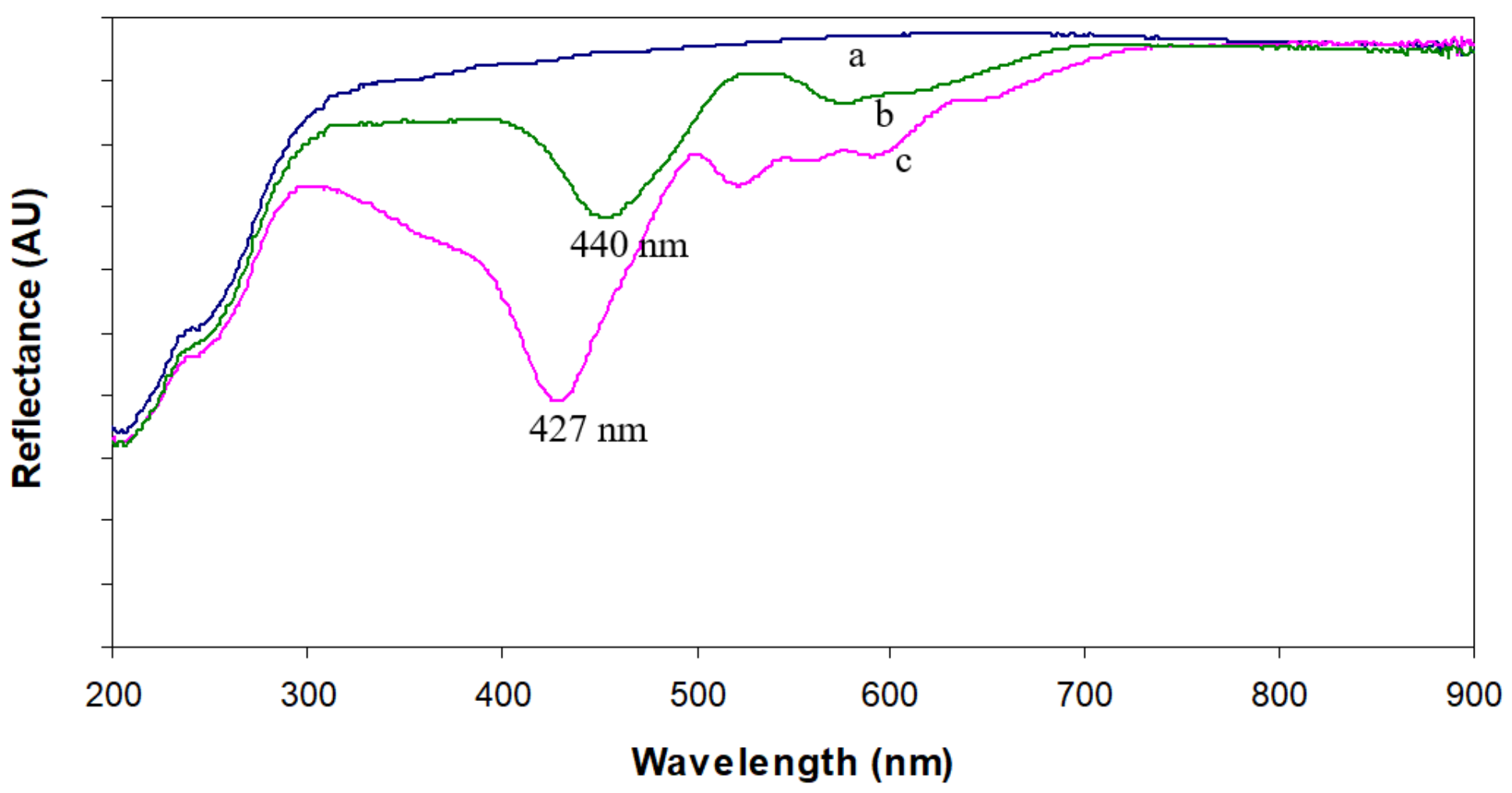

Figure 1

UV-Vis diffuse reflectance spectra of zeolite-Y (Si/Al:2.3) (a) adsorbed ZnTMPyP4+ (b) and H2TMPyP4+ (c).

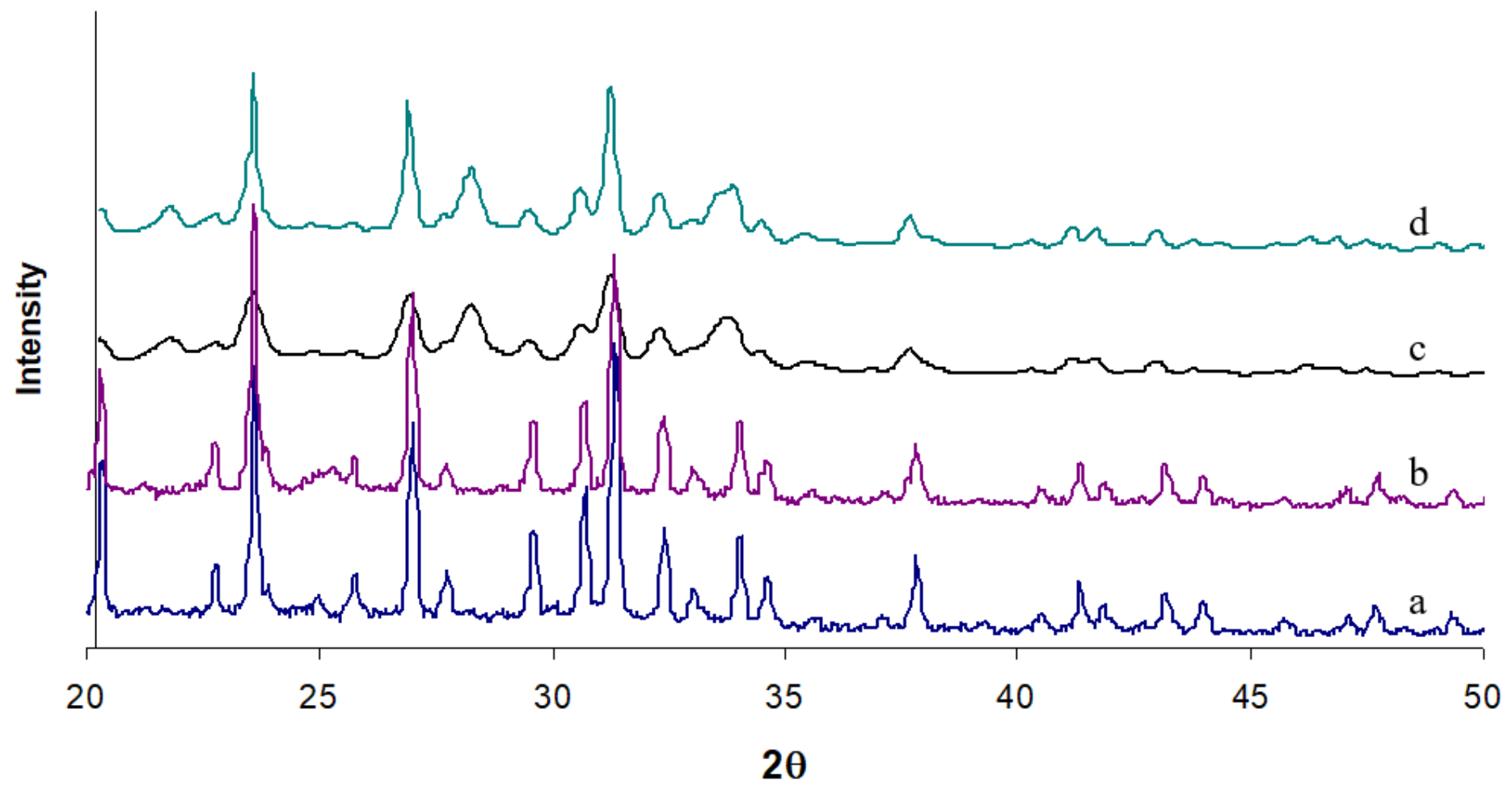




\section{Figure 2}

Powder X-ray diffraction pattern of zeolite-Y (Si/Al:2.3) (a), zeolite-Y (Si/Al:2.3) adsorbed H2TMPyP4+ (b), zolite-Y (Si/Al: 1.6) (c) and zeolite-Y (Si/Al:2.3) adsorbed ZnTMPyP4+ (d).

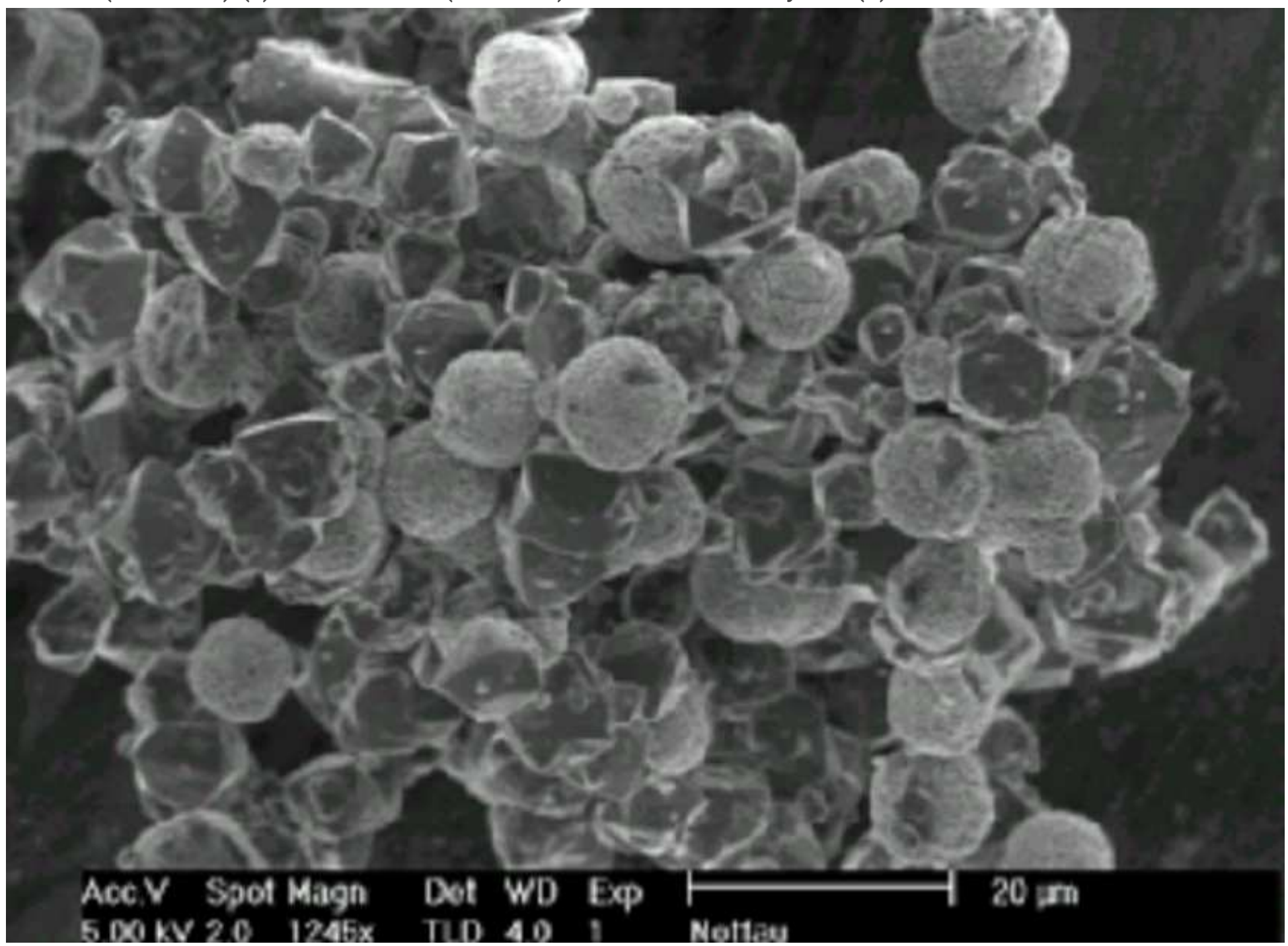

Figure 3

Scanning electron microscope image of zeolite-Y (Si/Al: 1.6) adsorbed H2TMPyP4+. 


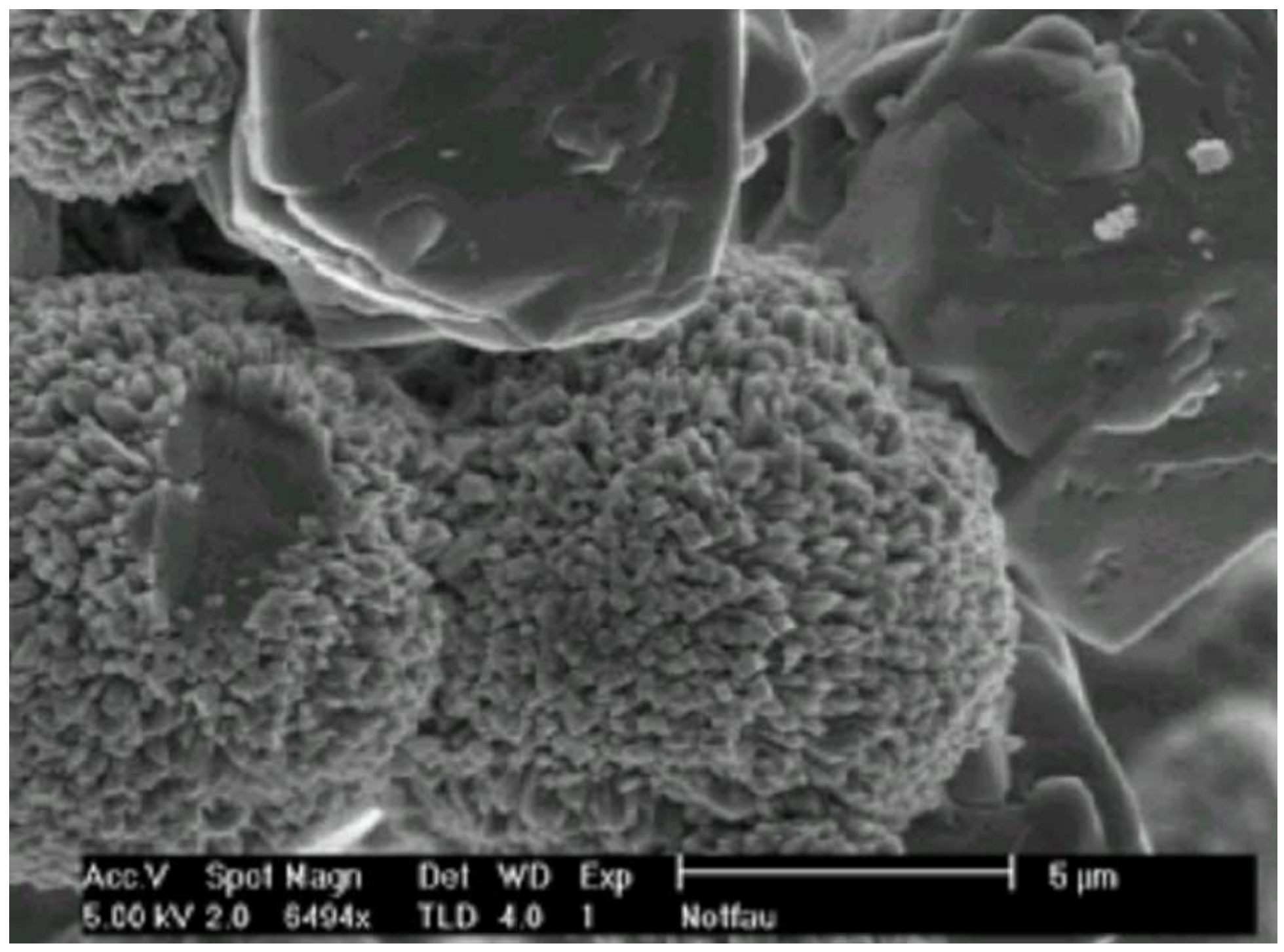

Figure 4

Scanning electron microscope image of zeolite-Y (Si/Al: 1.6) adsorbed H2TMPyP4+. 


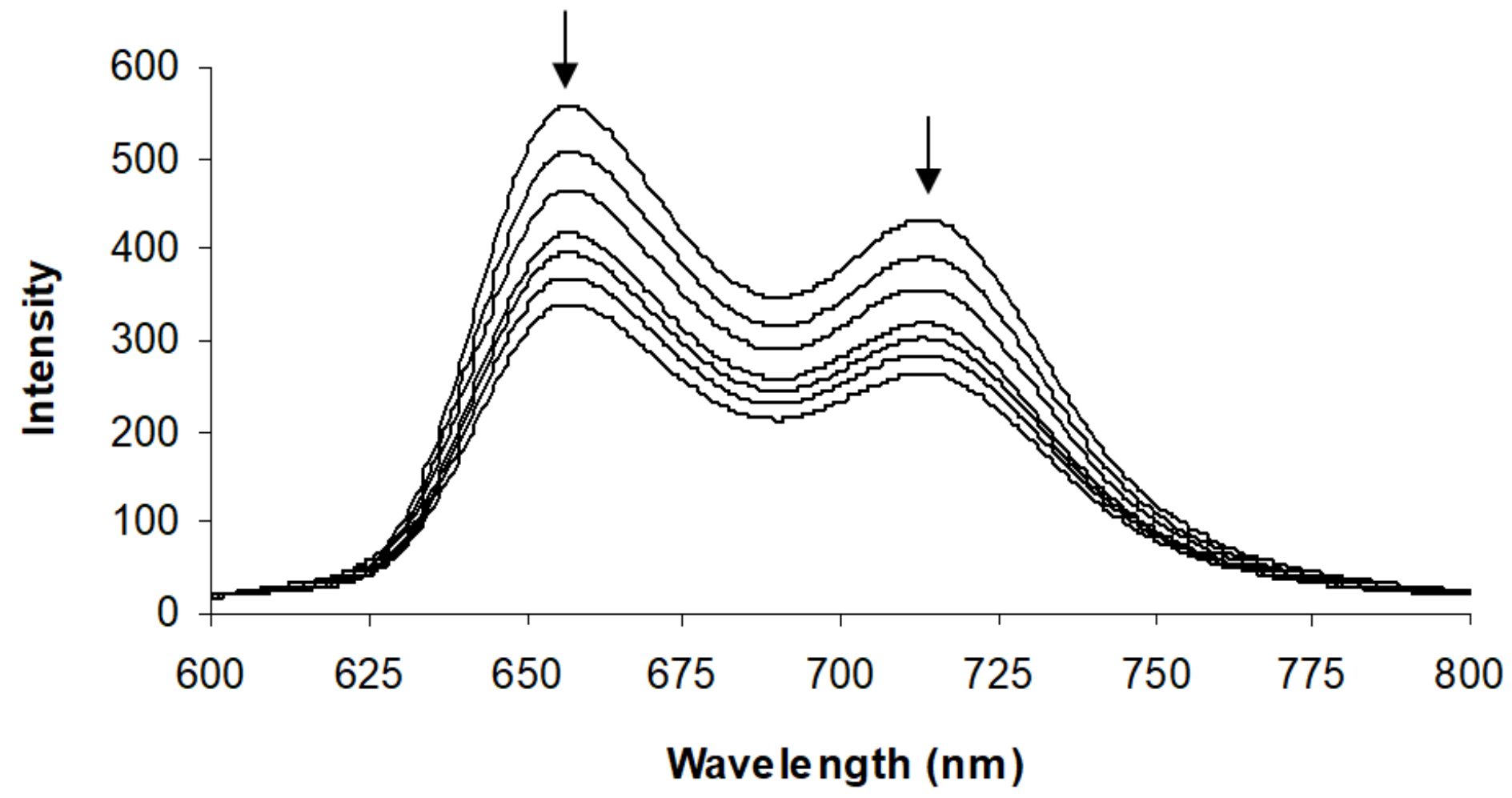

Figure 5

Fluorescence quenching of zeolite-Y (Si/Al: 1.6) adsorbed H2TMPyP4+ with various concentrations of ascorbic acid $(0-9.75 \times 10-3 \mathrm{M})$ in 1:1 glycerol: water.

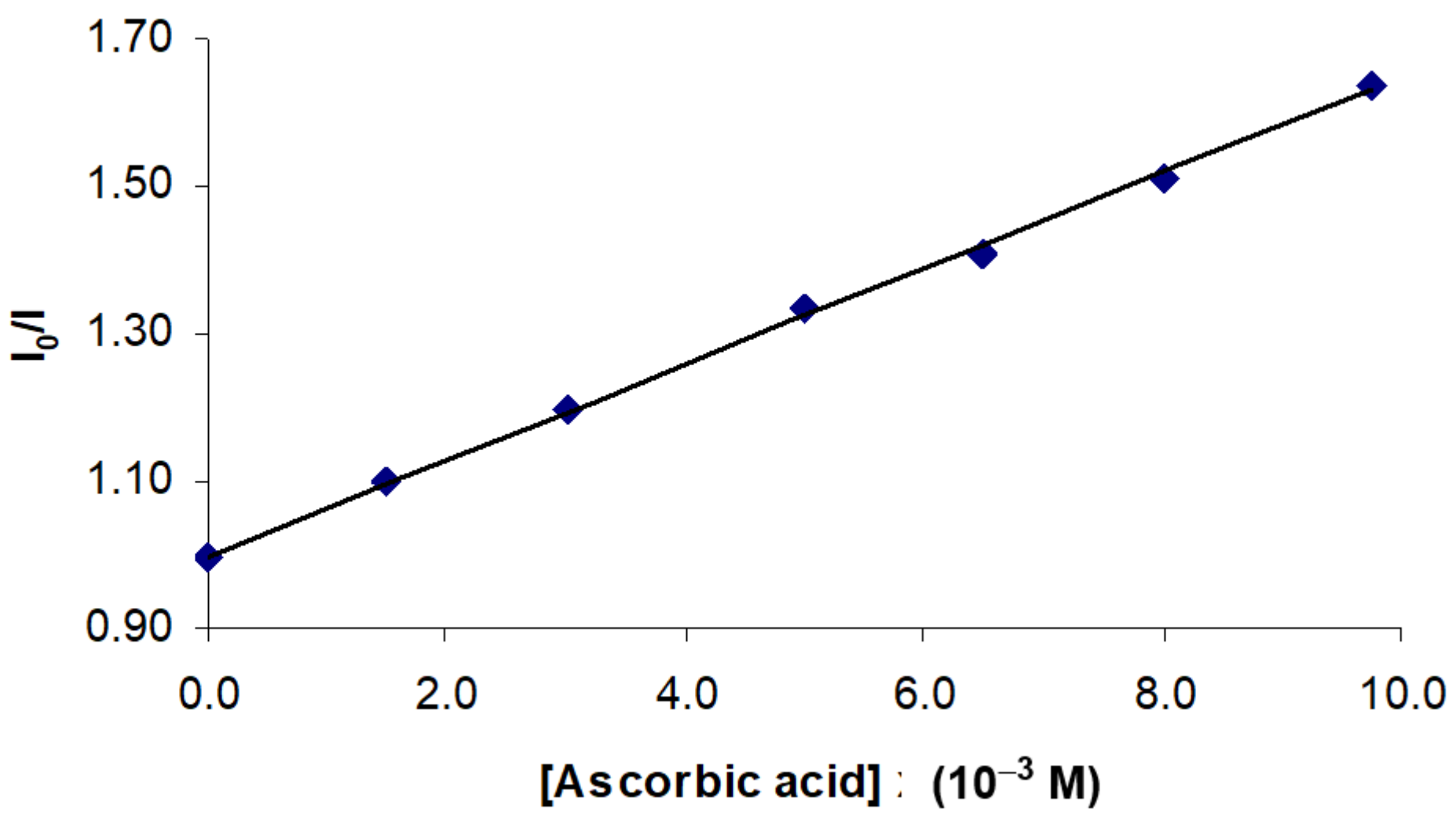


Figure 6

Stern-Volmer plot for the fluorescence quenching of zeolite-Y (Si/Al: 1.6) adsorbed H2TMPyP4+ with various concentrations of ascorbic acid $(0-9.75 \times 10-3 \mathrm{M})$ in 1:1 glycerol: water. 